\title{
A Qualitative Study of Consumers' Perceptions of the Affordable Care Act
}

\author{
Tofazzal Hossain ${ }^{1}$, Minh Hoang ${ }^{2}$, Steven Nguyen ${ }^{3}$ \\ ${ }^{1}$ BRAC Business School, BRAC University, Dhaka, Bangladesh \\ 2Saigon Institute of Technology, Ho Chi Minh City, Vietnam \\ ${ }^{3}$ Facial Cosmetics and Maxillofacial Surgery, PC: Richard J. Fraziero, East Longmeadow, MA, USA \\ Email: tofazzal.hossain@bracu.ac.bd,minhhtb@saigontech.edu.vn, snguyendmdmd@gmail.com
}

How to cite this paper: Hossain, T., Hoang M. and Nguyen, S. (2019) A Qualitative Study of Consumers' Perceptions of the Affordable Care Act. Theoretical Economics Letters, 9, 1569-1593. https://doi.org/10.4236/tel.2019.95101

Received: March 15, 2019

Accepted: June 22, 2019

Published: June 25, 2019

Copyright (C) 2019 by author(s) and Scientific Research Publishing Inc. This work is licensed under the Creative Commons Attribution International License (CC BY 4.0).

http://creativecommons.org/licenses/by/ $4.0 /$

(c) (i) Open Access

\begin{abstract}
Purpose: This study explores consumers' perceptions of the Affordable Care Act and its role in facilitating health insurance coverage for all Americans. Moreover, this research also examines how Hispanic consumers along the southern border of the United States and Mexico cope with healthcare related challenges. Design/Methodology: Narrative and observation research methods are employed to understand customers' experiences and emotions regarding healthcare issues. We first read the excerpts to develop an initial understanding of the participants' experience about healthcare. Then narrative analysis was conducted to further deconstruct participants' stories. Findings: Results show that although some Hispanic consumers in the United States hold negative views toward the ACA, they perceive the AHCA as a less favorable alternative. Additionally, the study reveals idiosyncratic coping mechanisms of uninsured Hispanic consumers along the Mexican border. Originality: The study explores new servicescape elements that enhance the services marketing literature related to healthcare.
\end{abstract}

\section{Keywords}

Affordable Care Act (ACT), Healthcare, Trumpcare, Obamacare

\section{Introduction}

Historically, the American healthcare system has often been a target of criticism, since it has not upheld the American belief that "healthcare is a right, not a privilege" [1]. As a result, the Obama administration introduced and enforced the Affordable Care Act (ACA) [2] [3], with the objective of providing access to affordable and high-quality health insurance to every citizen as well as reducing healthcare expenditure by the US government [4]. 
Currently, each state implements the Act by establishing health insurance exchanges, offering insurance coverage to the uninsured and small businesses [4] [5]. Despite the ACA's wide implementation, impending challenges exist, such as lack of control on insurance quotes, unexpected expenses (e.g. unnecessary tests), and continuous mark up of premiums [6] [7] [8]. Moreover, citizens also regard the policy as unfair since it provides free healthcare for poor individuals by taxing the upper class [9]. Consumers are not the only stakeholders that the policy impacts, physicians and healthcare providers have experienced financial and bureaucratic pressures due to the implementation of the ACA [10].

In March 2017, in order to repeal and replace the ACA, President Donald Trump introduced his own healthcare reform plan-known as the American Healthcare Act (AHCA), or "Trumpcare". Surprisingly, major healthcare organizations such as the American Medical Association, American Academy of Family Physicians, and the American Academy of Pediatrics have voiced concerns and lobbied against this GOP bill [11]. Two months later, the House of Representatives passed the bill [12]. This decision generated widespread backlash on social media and protests across the country [13].

There are mixed public opinions toward the AHCA. Few believe it is a better version of the ACA, while others think it helps widen the social gap between the upper and the lower classes [9] [11]. In particular, old, poor, rural, and chronically sick consumers are believed to be hurt the most under the AHCA, while young, rich, and urban consumers stand to benefit the most [14]. Some consumers and healthcare providers with neutral opinions worry about the uncertainties regarding the future of the healthcare industry [15].

The bottom line is that Americans are ambivalent with the implementation of both the AHCA and the ACA [16] [17]. Though many people show concerns, they want to keep the ACA, instead of repealing and replacing it with the AHCA [18] [19] [20]. Given the background, we are especially interested in exploring Hispanic consumers' perception of the ACA because the Hispanic population of the United States, as of July 1, 2017, was the largest ethnic or racial minority, constituting 18.1 percent of the nation's total population (58.9 million) [21].

Despite Hispanic Americans being the largest minority ethnic group in the United States, there is a dearth of research that examines their experiences with the ACA and their adaptation process to changes in the American healthcare system. Therefore, the purpose of this paper is to explore consumers' experiences with the ACA in USA, by reviewing inter-disciplinary literature stemming from services marketing, healthcare marketing, and public policy. Moreover, this research paper also shows how the Hispanic consumers along the border of USA adapt with the healthcare services of the United States and Mexico.

Among the one million residents in Hidalgo County, 33\% are under 65 years of age and lack health insurance [22] [23]. Diabetes rate is especially 
high in this area, where one in four residents suffers from it [24]. Additionally, Hidalgo County is one of the largest urban areas without a public hospital and it is located along the border of the United States and Mexico. Therefore, the current local healthcare providers lack sufficient facilities to meet the local demand [25]. Consequently, the lack of availability of clinical care specialties in the Rio Grande Valley forces patients in the area to travel to different cities of the United States or of neighboring Mexico.

Through narratives attained from in-depth interviews [26], this research allows further deconstruction of micro-stories and uncovers the grand narrative among Hispanic health care consumers in South Texas. In the following parts, the literature review, methodology, findings, theoretical and managerial implications are described in detail.

\section{Literature Review}

The study of services marketing began with the realization that consumers view products and services differently. This stream of research resulted in the expanded 7Ps of marketing [27] and the SERVQUAL scale [28], among many other contributions. Transformative service research emerges from the services marketing research steam and focuses on consumers' well-being through services [29]. Aside from financial outcomes of service [30] [31], research priorities in services marketing now include issues such as consumer union [32], quality of life, social justice [33] [34], and sustainability [35]. Extant literature emphasizes the role of healthcare and health insurance as products and services that enhance quality of life for consumers, in particular low-income consumers [36].

According to [37], healthcare services are highly complex and directly affect quality of life. Hence, this subject requires specific research attention [38]. In terms of the four characteristics of service (e.g. intangibility, high levels of credence qualities, inseparability, and heterogeneity), healthcare sector also shares the attribute of services marketing [37]. To be specific, the core benefits of healthcare are largely intangible; for example, medical diagnoses, treatment, and patient education [37]. Additionally, healthcare services are inseparable since they require patients to be physically present in order to consume the service, and they are perishable as they are created through staff resources and expertise [37]. The rapid introduction of technology (e.g. remote robotic control and tele-health) in the healthcare services [39] [40] makes the healthcare services as high credence based services because they are complex to evaluate even after consumption [37]. However, healthcare services are also unique in several aspects. For example, whereas customers may be willing participants in a service transaction, patients are often sick and under stress, and they may not necessarily enjoy a hospital environment where the treatment they receive triggers pain. Additionally, healthcare services require patients to reveal physical or emotional private matters, which oftentimes are considered as sensitive information. Lastly, healthcare pro- 
viders also undergo heightened stress, as the outcome of their service may be life or death [37].

Though healthcare services are often regarded as a unique type of service, extant research shows the application of the 4Ps as a successful marketing tool in this context [38]. [38] uses a hospital's pricing strategy of their heart check-ups to illustrate the use of the price element. The example of an international pharmaceutical manufacturer investing promotional dollars to educate neurologists on a new migraine medication illustrates the use of the element of promotion [38]. Finally, [38] argues that hospitals make use of place and location as a competitive advantage over other hospitals that may offer similar services.

Aside from the regular 4P's, [27] argue that 3 additional P's should be added when marketing services: people, physical evidence, and processes. These are all part of healthcare services in the form of doctors, nurses, and additional staff (people); medical equipment, recovery rooms, and staff uniforms (physical evidence); procedures used to deliver the service (processes). This last $\mathrm{P}$ in healthcare has recently undergone changes with the introduction of health information technology (IT) in order to improve communication processes [41], though it has encountered some resistance [42]. In order to repel this resistance, the government in 2009 introduced the Health Information Technology for Economic and Clinical Health (HITECH) Act [43].

\section{Marketing and the ACA as a Public Policy}

Many Americans are dissatisfied with current healthcare policy in the US [44] [45]. A salient complaint is that private agencies with profit driven goals govern many existing healthcare services, resulting in high cost for the consumer and inefficient or discriminatory policies [46] [47]. Many cannot afford insurance [46] and others lose coverage when laid off or when changing jobs [48]. Popular media reports lack coverage as a contributing factor to the thousands of deaths that happen in America every year [49].

Furthermore, data collected from studies conducted since 2007 suggests that policies that aim to reduce coverage significantly harm the health of individuals with chronic conditions and lower incomes [50]. [50] suggest that the Medicaid expansion driven by the ACA has led to more resources dedicated to healthcare, which enhanced mental health and well-being, however these benefits come at a societal cost.

Policy makers are introduced the ACA with the goal of providing more Americans access to affordable and high-quality health insurance, while reducing healthcare spending in the US. The ACA is a healthcare plan for America, signed by President Obama on March 23, 2010; the Supreme Court upheld it on June 28, 2012 in order to expand the affordability, quality, and availability of private and public health insurance. Aiming to minimize the number of uninsured Americans and make healthcare more accessible and 
affordable, this act advocates-“Access to healthcare is a human right". In this regard, the Congressional Budget Office expects that about $94 \%$ of Americans will access the healthcare coverage available while staying within the budget of $\$ 900$ billion and reducing the deficit over the next 10 years [51]. Currently, approximately 20 million Americans remain insured under the ACA [52].

In the short term, states within the US will take the main responsibility of establishing health insurance exchanges by regulating marketplaces so that the uninsured and businesses have insurance coverage [52]. The ACA requires all large businesses (50 employees or more) to insure employers, and grants tax breaks to small business (less than 50 employees) that do [53]. Eleven states and the District of Columbia currently operate their own exchanges; five states run their own exchanges using a federally supported website, while the rest of the exchanges function as a state/federal partnership at different levels [54]. Although such political developments may indicate that American society embraces the ACA, consumers have also voiced negative opinions against it for not having a well-defined population of beneficiaries and for its diffusing benefits [55] [56] [57]. Some argue that the ACA is unsuccessful in filling the gaps in contemporary insurance consumer needs [58]. Critics argue that the ACA treats different groups of Americans in different ways at different times [59]. Critics suggest that government efforts to explain the law, promoting the enrollment of eligible populations into new benefits, and mobilizing public support will be a lost effort [60]. The long-term challenges faced by ACA have mainly been cost reduction and increase in quality; however, research suggests that both of these goals have been arguable achievements for the ACA [61].

Though public opinion regarding the ACA has been divided since the beginning, a recent Kaiser Family Foundation poll finds that $45 \%$ of Americans have a negative view of this bill [9]. Citizens are unhappy with the healthcare plan for various reasons, but the main concerns are the breach of citizens' freedom to choose whether they want to be covered, and the financial burden it imposes on high income earners in the form of taxes needed to subsidize coverage for low income enrollees [9]. Others are also unhappy with the high premiums and deductibles that should be "affordable" [9]. Not only is the ACA receiving backlash from concerned citizens, politicians such as House Speaker Paul Ryan have also voiced their disapproval of the bill [62].

Business owners are also reportedly unhappy with the ACA. A recent survey conducted by BizBuy sell (a marketplace for small businesses) revealed that $60 \%$ of 700 small business owners were in favor of repealing the ACA [63]. The rising premiums and high deductibles have become a financial strain and many owners have opted to pay lower premiums at the cost of higher deductibles, which oftentimes results in unpaid bills for healthcare providers [63].

Various media outlets have debated on the advantages and disadvantages 
of the ACA endlessly, with the topic gaining even more interest in the light of the AHCA. Some evidence the pros while some argue the cons of the healthcare plan. Thus, there is a need for in-depth study on this topic to explore consumers' experiences with the ACA and how they adapt with the inadequate the healthcare services in the South-Texas of the United States.

\section{Methodology}

We employed an ethnographic approach to make sense of the text [64]. Ethnographic research method has been widely accepted in the marketing literature [65]. Moreover, there has been several critical studies conducted to understand and improve the ethnographic research methodology; For example, [66] and [67] made great effort to further explore this technique. This research method helps to provide very minute details [68]. Researchers can rely on self-report of the informants and observe informants in the natural environment [69]. Among the various ethnographic research methods (e.g. observation, in-depth interview and narrative textual analysis), we choose to use in-depth interview to explore participants' experiences and emotions regarding healthcare issues. According to [70], the in-depth interview is appropriate to elicit individual experiences, opinions, and emotions for some healthcare issues, especially personal issues around the social status, privacy and other sensitive questions.

\section{Data Collection}

Participants were recruited in the Rio Grande Valley (RGV), located in South Texas, where $93.6 \%$ of the population is Hispanic [71], most of whom are first or second generation of immigrants. Therefore, RGV culture is a crossroads between American and Mexican cultures.

We employed purposeful sampling and snowballing technique to recruit participants (for both phase 1, and phase 2), and audio recorded all interviews under participants' consent. Additionally, we recorded mannerisms and body language in the field notes, and transcribed interviews into electronic files for future analyses. Interviews lasted an average of 45 minutes. This study is conducted in two phases. Several in-depth interviews were conducted during two phases at two different points in time-fall of 2014 (10 participants) and summer of 2017 (11 participants), which makes a total number of 21. Despite the small sample size, in-depth interviews are quite effective in uncovering consumer experiences, as the large amount of information provided allows comprehensive deconstruction of meanings.

Initially, we tried to build rapport with the interview participants and gave a brief description about the goals and purpose of the research to the participants, as [72] suggested. Confirmability of this study is ensured through securing records of audio texts, which enables us to go back to the audio and check the information again. The audio interviews are very common form of 
data collection in marketing research [73]. Triangulation is achieved when the same texts are checked by different authors and found the same meaning. To ensure integrity and anonymity, we did not use original names. The entire dataset describes participants' opinions and experiences; however, we describe only the macro-narrative found there. Therefore, the study represents only a small portion of participants' responses. See Table A1 for participants' demographics.

\section{Data Analysis}

We analyzed data by integrating interview transcripts and field notes, and employed a process of phenomenological reduction, and narrative analysis based on interview transcripts. The goal of this method is to have an in-depth understanding of the way people create meanings in their lives and the way they make stories to interpret the world [74].

Narrative analysis uses a holistic approach to discourse that preserves context and particularity [64]. Sequence and consequence make texts into narratives; one researcher selects, organizes, connects, and evaluates events as meaningful for particular audiences.

Firstly, we read the transcript in order to obtain an initial understanding of each participant's experience with healthcare and the ACA. Secondly, we conducted the narrative analysis, and examined the transcripts in terms of what each participant's experience and consideration with ACA. Through the interview, we found that participants have concerns about healthcare and the ACA.

Based on [75], the analysis includes "what" participants know of the ACA and "how" participants experienced the ACA based on the transcripts. The "what" indicates the features of the ACA and is acquired directly from the interview. The "how" question aims to capture how they perceive the features of the ACA, and it includes the efforts, emotions, and feelings they experience which some of us coded. During this process, we grouped all transcripts based on the content and meaning similarities, then created categories regarding different themes based mostly on the psychology or feelings expressed by participants. There are two different levels of categories: the upper level or more general categories are derived from the research aims, while the lower level or specific categories are usually derived from multiple readings of the raw data [76].

\section{Findings}

We based participants' behavior traits on the provided statements, we then extracted each trait by making use of logical interpretations, which will serve as support for recommendations provided later in the manuscript.

\subsection{Phase One-Fall 2014 (Experience with the ACA) \\ Uncertainty}


Some participants were skeptical when exposed to uncertain situations dealing with information security. This made them reluctant in processing enrollment that required their personal information, such as income. Alex revealed these fears in his statements:

"I saw something on the news, when they ask me about my social, then I stopped.... I was very, very concerned, I was giving my income information. I was scared to do it, and I was scared not to do it [buy Obamacare]" (Alex, age is not available).

Alex felt hesitant to provide his personal information when needed because the news exposed him to stories about information piracy. Alex revealed that his fear of disclosing his personal information hampered his decision of enrolling in the ACA. Similarly, uncertainty also arose from the lack of information as evident in Alejandro and Daniel's interviews:

“My dad heard about it and wanted to get information, but he didn't understand when he called and we were just very confused" (Daniel, 26).

"I have heard from people about the Obamacare. People talk about it... My neighbors talk about it... My coworkers talk about it during lunchtime... I have no idea what it is about and how it is different from other healthcare insurances..." (Alejandro, 29).

In Alejandro's case, all of the information that he has regarding the ACA was obtained through word-of-mouth. The individuals providing him information were somewhat confused, resulting in Alejandro becoming just as confused when receiving the information. There was no official source for him to get relevant information on this health insurance. However, he did not have an immediate need to have health insurance at that moment.

Although Daniel's father was aware of the policy and was willing to learn more about the insurance package, they "were just very confused" when they tried to get more information. Unlike Alex, who could choose if he should proceed, Daniel and his father simply could not continue because the lack of information stalled them. This confusion resulted in a dead end.

Similarly, elderly respondents also reported misconceptions regarding the ACA since they did not have access to the internet. When they were able to go online, the information they encountered was so overwhelming and unreliable they were unable to make sense of it:

"My eyes are very weak lately... I cannot read much on the computer. It hurts my eyes... I know I need to read about what is called Obamacare... But not now..." . "They say it [Obamacare] is affordable... But affordable to whom... Everyone? Or only the rich?" (Bernado, 85).

"Yes, yes, what is affordable? I don't understand... It can be affordable to some rich one but may be not to me... I am retired... I have no income..." (Maria, 83).

"I have been reading about Obamacare on the Internet... Some say it is good for everyone... Some say it is going to kill the healthcare industry and its 
quality..." "Hmm... We need to wait and see... Too early to see..." (Romeo, 85).

Since Romeo was a manager at a hospital in San Antonio for 30 years before he retired, he was familiar with the healthcare system. However, he was confused with the debates on Obamacare as well. The fragmented opinions regarding the ACA along with the lack of reliable information made consumers extremely uncertain and reluctant to proceed with the enrollment process:

"People at my church talked about Obamacare sometimes... But none of the information is official... Nobody goes to our church to tell these old people what it is... I guess we are too old for the government to pay attention..." (Madelia, 76).

Even though their own health insurance covered them, the elderly expressed interest in knowing more about the ACA, it seemed that they could not get reliable information anywhere.

\section{Resentment}

Participants also mentioned that the application process was frustrating. The amount of forms and information needed to apply upset them and discouraged them to continue, as exemplified by Lydia's experience:

"It [applying for Obamacare] takes time. You need to input 20 - 30 pages to do it or more. A lot of background information. I think it is a hassle. My mom rather pay for the penalty than go through all that. My family never goes to the doctor" (Lydia, 20).

Lydia mentioned not only the complicating procedure, but also her mother's unwillingness to pay the penalizing fee instead of going through the grueling application process. From Lydia's excerpt, it is assumed that her mother, like Daniel's father, was willing to enroll but refused to do so due to the frustrating application process. The resentment evidenced in Lydia's experience could be an extension of the uncertainty experienced by Alex when presented with a situation that jeopardized his personal information in his perspective. If Alexhad provided his personal information and had been willing to expose himself to risk of information theft, he would have faced the frustration and resentment caused by the application process just as Lydia's family did.

\section{Neglect}

It was also evident from the data, that various consumers just neglected enrolling in Obamacare. An example of such participants was Manuel:

"My parents don't have that [health insurance], so even though I qualify to be under their policy because of my age it doesn't even matter" (Manuel, 21).

As mentioned above, even though Manuel qualified to enroll, he failed to find it necessary since his parents did not even have health insurance. This was consistent with the fact that Hispanic consumers are highly dependent on trusted relationships with friends and family [77]. Moreover, this neglect also reflected his lack of awareness of the risks associated with lack of health insurance. He could think that obtaining health insurance should be a concern for his parents, not his. Similarly, this lack of awareness evidenced the fact 
that they largely disregard future situations where he or his parents may find themselves in need of serious healthcare.

Moreover, another reason why consumers decided to neglect their enrollment was of a financial nature. Aside from the frustration associated with the application process, Alex also expressed a willingness to forgo his ACA application because it was not affordable for him at that moment:

"They say it is affordable, but I can't afford to pay $\$ 170$ or so per month when I have to worry about rent and my parents. I don't think they thought this through. May work for others, but not here [the school media lab]" (Alex, $\mathrm{N} / \mathrm{A}$ ).

As stated above, the frustration associated with the application process and the unaffordable prices were enough to convince Alex that he should not enroll in the ACA. Regardless of his willingness to enroll, he would not have been able to do so if he did not have the economic capital to afford it in the first place. Coupled with his high acceptance to be penalized, financial unaffordability made Alex willing to neglect health insurance.

\section{Opposition}

Though Alex expressed his willingness to neglect enrolling for unaffordable health insurance in the US, he did not totally forgo healthcare. Instead of enrolling for Obamacare, Alex reveals that he would rather obtain his healthcare somewhere else than the US:

"We just don't need it. One time my mom got sick and we just went to Reynosa to visit the doctor over there for $\$ 500$ pesos. We got some medicine and came back" (Alex, N/A).

Alex's coping strategy with unaffordable ACA was to cross the border to visit a doctor in Mexico, who charged a relatively cheaper price ( $\$ 500$ pesos) than his American health insurance. Though Alex opposed Obamacare, he had access to other options (i.e. crossing the border) that were better suited for his needs. Unfortunately, having this option so readily available provided him with yet another reason to neglect enrolling for health insurance under the ACA, making him a strong opponent of the regulation. Similar to Alex, Manuel and his family preferred getting medication from Mexico:

"We have everything in Reynosa. It is just 15 minutes from here [the school] by bus... I visit my mom and sister every month so I get antibiotics from my house if need..." "No, you don't have to see the doctor to get the medication... You can get from any pharmacy... If you get fever, you go to buy tablets for fever..." "I buy medication for my friends here in school... They ask me to get for them tablets from Mexico whenever I go there... The medication is much cheaper there than here [the US]" (Manuel, 21).

Manuel purchased medication in Mexico not only for his personal use, but also for his friends in the US Manuel was not the only participant who expressed the same coping strategy, Daniel also mentioned that his father preferred to cross the border when seeking medical attention:

"My dad doesn't like it. He said we will just go to Progreso and get checked" 
(Daniel, 26).

Earlier in the interview, we assumed that it was the uncertainty experienced in the information seeking stage that persuaded Daniel's father to halt his enrollment in the ACA. However, with the mention of this cheaper option (i.e. seeking medical assistance in Progreso) available to them, made it clear that Daniel's father would purposefully neglect enrolling in the ACA. The same case mightapply to Lydia and her family.

A follow-up interview in phase 2 revealed that Daniel and his father really made and effort to learn more about the ACA (revealing a high level of customer engagement on their part), but later gave up their information search due to low credibility from their sources of information. Since Daniel's father omitted unaffordability as a reason to oppose the ACA (as Manuel did), it could be assumed that he may have been open to enrolling if he had found more trustworthy sources of information. In any case, it is clear that consumers living in a border town like Manuel, Alex, and Daniel's father were unwilling to continue with their enrollment process because there was a cheaper and more convenient option for them right across the border.

\subsection{Phase Two-Summer 2017 (Experience with "Obamacare" with "Trumpcare" on the Loom)}

\section{Uncertainty}

Previous experience with the ACA might influence potential consumers when exposed to the AHCA:

"A friend helped my dad apply [to Obamacare] because he was able to explain in Spanish, but now with this new thing [Trumpcare] he is scared that we will lose it again [health coverage]" (Daniel, 30).

Daniel revealed that despite the frustrating application process, his father invested the time and effort to apply for health insurance under the ACA. It was evident from his excerpt that a significant impediment in the information seeking stage was a language barrier. In the end, they resorted to a friend to help translate the information to Spanish. It is easy to see how they would be ambivalent in trusting the information they received as it was merely the interpretation of somebody else.

Despite their efforts, they were unsuccessful in their enrollment process. We can assume that Daniel's father would have asked the same friend to help with the AHCA enrollment, having shown an interest in obtaining American health insurance. Unfortunately, their previous negative experience with the ACA biased them and made them afraid of the application process with Trumpcare as well.

Similarly, other participants who had been successful in their ACA enrollment but had negative experiences during the information seeking stages were reluctant to repeat the whole ordeal with the AHCA. Sebastian's account echoes these sentiments as evidenced by his statement:

"I ended up getting it [Obamacare], but it took me 2 days to sit down and 
learn about the process. I have an uncle who works as a custodian and sometimes in the fields; people like him can't have time to learn. God only knows how long it will take me to learn Trumpcare" (Sebastian, 47).

Alex, similar to phase 1, was still reluctantto enroll due the fear of providing his information during the application process for the ACA:

"They asked too many personal questions... Like my social security number... my birthday... where I was born... [applied for Obamacare]" "Oh... God... I don't want to go through the same application again [with Trumpcare]... I have no idea what it [Trumpcare] is about... It [Trumpcare] must be very expensive". (Alex, N/A).

While Sabastian admitted he acquired the ACA only after struggling with the process for 2 days, Alex was still worried about his personal information. Subsequently, Alex obtained this health insurance because of the fear of facing penalties. The penalties for those who were qualified for the ACA but were not enrolled were high:

"The penalties are too high... It is almost the cost of Obamacare... I guessed I just had to pay for Obamacare to avoid the penalty... even I don't ever use the insurance..." (Alex, N/A).

Moreover, Alex was confused and disagreed about why he had to pay the penalty for not having the ACA. He believed the government should not have to force citizens to purchase health insurance. In other words, acquiring health coverage should be the consumers' choice:

"Yeah... There is a penalty for not having insurance... I have no idea..." "You must have Obamacare... You can't say you do not want a health insurance... even though you never use it..." "The penalties are deducted directly from your tax refund... They [the government] are bad..." "Trumpcare could be worse... Trump is rich... Trump never see poor" (Alex, N/A).

These negative experiences predisposed participants to be hesitant towards the AHCA's enrollment process. In other words, Alex did not like the penalties but he preferred staying with the ACA to the possibility of switching to the AHCA. He seemed rather uncertain about his healthcare future under the AHCA. Moreover, because policy makers could not guarantee the application process for the AHCA to be the same as the ACA, having gone through the application process once did not ease his anxiety.

Elderly respondents also expressed frustration with the potential changes looming over health insurance. They were afraid and uncertain of what the AHCA might entail. The ACA did not have a major impacton their current health insurance, but this new policy might. Moreover, these elderly participants seem to be oblivious to the AHCA:

"They [the government] keep changing [insurance policy]... We don't know if the latter is better than the previous..." (Romeo, 89).

"I heard from TV about the change... I watched TV every day... They [the news] also don't know what will happen" (Madelia, 80).

"Well... what they [the government] are going to do with my elderly's in- 
surance? Taking it away? Do I have to pay more? I have too many questions in my head..." (Bernado, 89).

"I heard that there will be a new Obamacare [Trumpcare]... I heard that from my husband. That's all I know..." (Maria, 87).

\section{Inaccessibility}

Again, financial unaffordability continued being abarrier. Though participants were aware of the risks associated with not having health insurance, they did not justify the necessary financial investment, as Sebastian stated in his account:

"We don't know anything about the bill [Trumpcare]. We don't know what is in it. It may be worse than Obamacare. John McCain is having a brain tumor, what will happen to him if he does not have insurance? Things happen to people like him, but he doesn't know what people like us go through. I already have tons of debt just for one fracture" (Sebastian, 47).

Sebastian clearly understood the consequences of suffering any type of health-related issue without health insurance as he compared John McCain to "people like us" who were blue-collar workers. He had the ACA and it seemed already a financial burden for him. However, the outstanding debt that already burdened him due to a fracture deterred him to consider health insurance as a viable option. Alex also discussed his experience regarding inaccessibility due to financial constraints:

"The Obamacare is too expensive. I am paying $\$ 447$ per month for the premium plan for myself. I am single, not so young anymore, and have some health issues. If my income is lower, I might be able to pay less. My income last year and this year just slightly came over the below rank but I have to pay the much higher premium rate. I am sure Trump will make it more expensive" (Alex, N/A).

Alex admitted that the premium plan under the ACA was too expensive for someone in his situation and expressed uncertainty regarding the prices that President Trump might implement. He stated that his income constrained him to pay higher prices, even though it was just slightly over the lower rank. His momentary concern became more poignant when he thought of the future possibility of having to pay even higher prices under the AHCA. This price uncertainty caused feelings of anxiety in consumers like Alex and Sebastian.

\section{Lack of information}

Lack of information continued being a barrier in phase 2. As illustrated in Daniel's interview, one of the reasons for this lack of information could be the dependence that Hispanic consumers placed on trusted relationships with family and friends. An example of this was Ana's experience:

"We don't really know what it is [Trumpcare]. My sister heard about it in the news, but nobody has told us anything or what to do. We have Obamacare because our neighbors have it and explained it to us" (Ana, 33). 
Though Ana and her mother were successful in enrolling to the ACA, it was only due to the help of a neighbor who took the time to explain the policy to them. However, because the neighbor had only explained the ACA, Ana and her sister were still very uncertain as to what the ACA was all about or how to enroll for it. Unlike Daniel's father, who despite his language barrier proactively sought information regarding the ACA, Ana seemed to be completely dependent on the information she received from informants she trusted: her neighbor in this case. This led us to believe that if there wasn't anyone in her trusted network that had had experience with Trumpcare, she would more than likely not receive (nor seek) any information about it. In Ana's case, she and her mother needed a trusted source in their network that had had previous experience with Trumpcare and that would actively engage them in the application process for them to enroll.

\section{Disinterest}

Finally, some consumers were completely disinterested in health insurance as exemplified by Karina's excerpt:

"Because we don't like to discuss about healthcare or Obamacare or Trumpcare among family and friends. We don't stress out about it too much. We (Hispanics) don't stress out too much about healthcare. So we don't concern too much about having insurance or not" (Karina, 42).

Similar to Ana, Karina and her family were not proactive in learning about insurance. The uncovered reason was similar to Manuel, who was not interested in the ACA since his parents did not have insurance in phase 1:

"We [Manuel and his family] still don't see the need of insurance... I go to Mexico to get medication... Nothing changes... I never see a doctor..." (Manuel, 24).

As Karina mentioned that they "don't like to discuss about healthcare or Obamacare or Trumpcare among family and friends", we assumed that her family did not have health insurance of any kind. Moreover, as Karina continued that they "(Hispanics) don't stress out too much about healthcare"; she evidenced her acknowledgement of the fact that her family and herself did not place much importance to healthcare nor health insurance. As opposed to Sebastian, who understood the risks associated with not having health insurance, Karina and her family either remained oblivious to potential risks in the future or just chose not to be concerned. Additionally, just like Ana's case, Karina and her family might be dependent on their own trusted network to make healthcare choices such as purchasing health insurance, if no one in their network had it, they might be very unlikely to seek out information proactively. Finally, having the option to seek out medical attention in Mexico might be an influential factor in their choice to forgo enrolling in health insurance of any kind. The older group seemed not so much concerned about the health insurance matter as long as their benefits remained the same:

"If my benefit [current health insurance] is the same, I don't care [about 
Obamacare and Trumpcare]... (Maria, 87).

"So far, I was able to do the regular checkup... Obamacare did not have any effect on me... I think Trumpcare will not affect the elderly like us [he and his wife]" (Romeo, 89).

\section{Favorable}

As opposed to other participants who have a quite humble educational and financial background in comparison, Diego, Macio, and Camila have at least a graduate degree and are part of the middle class. Thus, it is unsurprising to see that they have very different experiences with and perceptions of the ACA. Diego credited the ACA with giving him and his family the ability to obtain regular dental services, medical checkups, and medication:

"My little sister had her braces done two months ago... I went to see the dentist a few weeks ago...We [the family] all go to dentist twice a year... The services all are covered by Obamacare..." (Diego, age is not available).

Moreover, Diego appreciated that the ACA offered deductions on his medications. He had several critical health problems. Thus, the deduction offered through the ACA helped him and his family significantly. Without the co-pay policy from the ACA, he and his mother who both have diabetes could not afford the expensive medication from pharmacies. The full price of these pills was too expensive for them. They have to consume special medications regularly for their respective medical conditions:

"My medication is very expensive. I have diabetes and other issues. Man... without Obamacare, I can't afford this bottle of the pills... Like... for example... if I get from CVS without the insurance, I pay like $\$ 200 \ldots$ but with the insurance, I pay like $\$ 14 . .$. huge difference" "My mom has diabetes too. My family is lucky to have this insurancefrom my Dad... And my Dad gets this insurance from his company" (Diego, N/A).

To Diego, the monthly payment for the ACA was reasonable since the insurance was helpful for the whole family, including his and his mother's diabetes medication and his younger sister's new braces. He considered their current family plan to be the best option for them, compared to having an individual plan just for himself. Consumers like Diego and his mom, who suffer from medical conditions, held favorable attitudes towards health insurance because they had experienced its benefits:

"We pay like $\$ 2000$ per month. It is not much. I am talking about the insurance for the whole family. My dad's company pays most of it. We just pay some..." "If I get insurance by myself, it is $\$ 500$ to $\$ 800$ at least..." (Diego, N/A).

However, Diego was about to reach the age limit to be covered under his father's insurance. He was worried about the cost he might face. To Diego, the family plan's cost was inexpensive compared to an individual plan. Thus, the ACA was under specific circumstances only:

"Next year, I $m$ too old to be under my dad's insurance... Man, it is too cost- 
ly to buy Obamacare for a single person". "...I can't stay in the family plan after this year" (Diego, N/A).

Similar to Diego, Macio considered family plan under the ACA as very affordable. Moreover, to Macio, his current plan was the cheapest compared to others offered byprivate insurance companies:

"This [his insurance] is the cheapest out there. We would not be able to get better deal... I have my wife and her daughter under my insurance". "Other companies [private insurance companies] charged a lot... I have several health issues... My wife is too... She has her own problem because of aging..." (Macio, 68).

Furthermore, due to Macio's health history, he might not be qualified to purchase a plan from many insurance companies even if he was willing to pay. These private companies could reject him if they believed him to be high-risk given his medical history:

"Under Obamacare rules, they [insurance companies] have to sell to me this health insurance". "They can't reject me... It is against the law..." "I am able to have health insurance because of Obamacare" (Macio, 68).

Macio's wife, Camila, also agreed that without the ACA's policy they would not be able to have health insurance from private insurance companies. For elderly consumers who suffer from various medical conditions, such as Macio and Camila, undergoing surgery without health insurance would be a very difficult situation. However, they had not been able to get the insurance before even though they were willing to pay:

"Yes... We got this plan thanks to Obamacare..." "I tried many times before... I couldn' t..." "They [insurance companies] looked at my diagnoses... They said no..." (Camila, 68).

Under their current ACA plan, the old couple were able to have the surgeries they needed. Without such insurance, they might not have a solution for their ailments, they might even have had to tolerate the pains. Alternatively, they might have needed to bear a huge financial burden after the treatments:

"I had my back surgery just last week in Houston. The insurance covered the cost. Finally, I can walk now... It [the back pain] was for almost twenty years". "My husband is going to have his [back surgery] next month. It is already scheduled. He has his surgery in Houston too... same doctor" (Camila, 68).

However, the couple were worried that the AHCA would modify the current policies and the benefits they were enjoying. They were frightened that the AHCA might favor the private health insurance companies and neglect those in need like themselves. They stated that they hoped the ACA could stay the same. In other words, they were against the AHCA:

"Next year, it [their health insurance] would not be the same. It could be much more expensive that we cannot afford... Or we have to go with insurance that does not cover our surgeries..." (Macio, 68). 
"I am sure that none of plans can be as good as Obamacare" (Camila, 68).

"They [other people] do not understand... Obamacare is very good... They will see..." "They should not trust the media... They [the media] are political... I was a nurse for 40 years... I see the benefits of Obamacare". (Camila, 68).

However, this couple agreed that the ACA could be very difficult and complicated to understand. It took them a lot of time to comprehend the advantages and disadvantages of each of the plans under the ACA:

"I spent three days... sit down... and just read about Obamacare... 3 days... remember I am a physician... and it still took me that long..." "Yes, it is complicated... I agree... But you need to read by yourself... You cannot just believe what others tell you..." "I had to make a table to compare the plans... One side is about the cost and one side is about the benefits". (Macio, 68).

"Yes, it [Obamacare] is difficult to understand". (Camila, 68).

\section{Discussion and Theoretical Implications}

Our findings from both phases are consistent with those of [77]. Participants revealed uncertainty arising from situational factors, such as exposure to information piracy or the lack of reliable information. Other participants implicitly suggested that they were actually unaware of the risks and consequences of not having a health insurance plan. Echoing [77] findings, participants declared high dependence on word-of-mouth from trusted sources in their networks, such as family and friends, to make decisions in the healthcare domain. Financial constraints emerged as the main deterrent to obtain health insurance under both the ACA and the AHCA, as participants acknowledge their willingness to pay the penalizing fee for their lack of enrollment instead. Another emergent deterrent was the complicating enrollment procedure. Some participants disclosed their preference for obtaining healthcare in Mexico to avoid such complications and financial burdens.

On the other hand, some participants showed a high level on engagement during the information seeking stage and enrollment process. However, their lack of reliable sources of information paired with a language barrier discouraged them to enroll in the end.

In phase 2, the idea of the AHCA was included in the interviews, together with the ACA. Text generated from phase 2 data collection revealed that negative experiences with the ACA (frustrating application process, and confusion during information seeking stage) negatively affected participants' attitudes towards the AHCA and their intentions to enroll in the new health insurance policy. Besides, having a positive experience with the ACA may lead consumers to develop negative attitudes towards the AHCA.

Encouragingly, our findings in phase 2 suggest that though Hispanic consumers may perceive several barriers to enroll in health insurance, trusted individuals in their social networks, such as family members, greatly ameliorate this process as they encourage and guide consumers. Moreover, the pen- 
alty for not having health insurance pressures consumers to acquire the ACA. Thus, it helps increase the number of people who have some type of health insurance across the US.

Additionally, in phase 2, the attitudes toward the ACA are significantly different between those who possess higher education, are under a family health plan, and have health issues versus those who possess lower education, have no insurance or have individual health plan, and are healthy. Specifically, the early group show strong preferences toward the ACA since it helps them obtain health services and medication they need. They would have to pay much more under other policies. They were also capable of reading the materials related to the ACA and identified the benefits that this healthcare policy could provide. Moreover, the family plan seems much more affordable than the individual plan under the ACA. In other words, the ACA seems to provide more support for families than single consumers.

In contrast, the latter group expressed negative attitudes towards the ACA because they are healthy. Thus, the cost of acquiring health insurance is not justified since they see no need for it. Moreover, they tend to obtain information about the ACA mainly from the media and their close-knit networks which may result in acquiring unreliable information. Thus, they might not understand the costs and benefits that the ACA might present to them.

Based on our findings, we concur with recommendations made by [77]. Additionally, strengthening reliable communications by including health insurance education in school is a proactive strategic implementation. Though education does not tackle all of the barriers present in health insurance enrollment, it does mitigate the uncertainty that consumers may face due to lack of information about the topic.

Overall, the findings at current stages seem to indicate some potential gaps: 1) a need for specific marketing concepts in healthcare insurance context, and 2) how the ACA reflects the transformative services marketing direction initiated by [29]. This work also provides preliminary data regarding consumers' cognitive (awareness, discouragement, neglect), andaffective (fear, insecurity) reactions to the ACA and the AHCA, as well as theircoping strategies when unable to enroll in health insurance (i.e. seeking access to alternative healthcare services). Finally, findings are limited to specific consumer experiences as evidenced by results of Phases 1 and 2, thus, may not have captured an exhaustive array of experiences (if any) of how other customers experience the ACA.

\section{Managerial Implications}

Their high dependence on trusted relationships caused two major issues for Hispanic consumers in their quest to obtain health insurance, specifically: 1) lack of awareness of the policies available, and 2) lack of reliable sources of information. As evidenced in our interviews, some consumers were interest- 
ed in enrolling or even learning about health insurance policies simply because trusted family and friends did not have health insurance or were not interested in enrolling either. Even in cases when consumers were proactively seeking out information, they abandoned their efforts if they encountered difficulties with the application process and no one was around to guide them through it. When consumers actually had someone willing to instruct them, they were successful in their enrollment as exemplified by Ana's interview where the neighbor helped her and her mom. On a more positive note, addressing this dependence properly could provide a means for a more effective communication between policy makers and consumers.

Moreover, marketers should spend more efforts to alleviate the language barrier experienced by Hispanic consumers. Making sure that Spanish speakers are available when policy makers target the Hispanic community will ensure that communication will flow smoothly between consumers and service provides increasing the probability of enrollment. Moreover, this could increase awareness among Hispanics regarding the risks of not having health insurance and the benefits of the same.

Another issue that came to the fore from our interviews relates to the proactivity with which Hispanic consumers searched for information regarding health insurance. The data revealed a tendency from Hispanic consumers to rely on others to provide them with such information, meaning that public healthcare workers were only able to help those who actively reached out for their assistance. A potential solution would be to educate consumers about healthcare and health insurance in high school, this would ensure that consumers would at least have the basic information to be able to reach out and continue on the information seeking stage on their own should they need to. These same consumers could then act as trusted informants for family and friends by providing information through word-of-mouth, thus increasing awareness of health insurance among their social networks.

Based on our findings, policy makers should also simplify enrollment process, as this was a major deterrent for consumers who were willing to obtain health insurance. Several respondents, such as Marcos, expressed feeling frustrated with the enrollment process which led them to quit their quest for health insurance altogether. Simplifying enrollment process would encourage more consumers to apply without having to seek external support.

Finally, it became evident that the cost of health insurance was in itself an influential barrier of enrollment to respondents. Though our participants reported a low annual income, they were willing to incur the costs of crossing the border to obtain medical care since enrolling in health insurance in the US is a more expensive option for them. Policy makers should consider areas around the border where consumers prefer to travel to Mexico than enroll in health insurance when calculating premium prices, this would make health insurance in the US a more attractive option compared to crossing the border. 


\section{Limitations}

First, readers should interpret current findings with caution due to small sample size. This factor limits us in depicting the bigger picture of the subject matter. Future research should attempt to design a survey-based study with an acceptable sample size to test and achieve generalizability of experiences. Second, these findings are context dependent to Hispanic consumers in the RGV and thus cannot echo experiences by other minority groups. Having said this, our findings are transferrable to other similar contexts (i.e. low-income areas with a large portion of Hispanic population). Future research could focus on examining experiences of different ethnicities of consumers to achieve an exhaustive understanding of consumer experiences with the ACA and the AHCA.

\section{Conflicts of Interest}

The authors declare no conflicts of interest regarding the publication of this paper.

\section{References}

[1] Papadimos, T.J. (2007) Healthcare Access as a Right, Not a Privilege: A Construct of Western Thought. Philosophy, Ethics, and Humanities in Medicine, 2, 2. https://doi.org/10.1186/1747-5341-2-2

[2] HealthCare.gov (n.d.) Patient Protection and Affordable Care Act. https://www.healthcare.gov/glossary/patient-protection-and-affordable-care-a ct

[3] Rosenbaum, M.S., Corus, C., Ostrom, A.L., Anderson, L., Fisk, R.P., Gallan, A.S. and Williams, J.D. (2011) Conceptualization and Aspirations of Transformative Service Research. Journal of Research for Consumers, 19, 1-6.

[4] ObamaCare Facts (n.d.) ObamaCare/Health Insurance Exchange. https://obamacarefacts.com/obamacare-health-insurance-exchange

[5] Leonard, K. (2016) ObamaCare's Success Hinges on States. https://www.usnews.com/news/articles/2016/01/12/for-obamacare-who-is-r unning-states-matters

[6] Gorin, S. (2013) The Future of the Affordable Care Act-A Social Work Perspective. http://www.socialworktoday.com/archive/012113p22.shtml https://doi.org/10.1093/acrefore/9780199975839.013.830

[7] GOP.com. (2016) ObamaCare's Costs Are Spiraling out of Control.

[8] Young, J. (2012) Healthcare Spending on Unnecessary Tests Discouraged by Major Medical Groups.

[9] Luhby, T. (2017) Why So Many People Hate ObamaCare. http://money.cnn.com/2017/01/05/news/economy/why-people-hate-obamac are/index.html

[10] LaMotte, S. (2017) What Doctors Think about the Affordable Care Act. http://www.cnn.com/2017/01/13/health/obamacare-doctors-opinions-aca/inde x.html

[11] Naylor, B. (2017) Medical, Hospital Groups Oppose GOP Healthcare Plan. http://www.npr.org/2017/03/09/519450642/medical-hospital-groups-oppose -gop-health-care-plan

[12] Kaplan, T. and Pear, R. (2017) House Passes Measure to Repeal and Replace the Affordable Care Act. 
https://www.nytimes.com/2017/05/04/us/politics/health-care-bill-vote.html

[13] Wishingrad, E. (2017) Across the Country, Signs of Death Dominates AHCA Protests.

http://www.pbs.org/weta/washingtonweek/blog-post/across-country-signs-de ath-dominate-ahca-protests

[14] BBC (2017) Trump Health Bill: Winners and Losers. http://www.bbc.com/news/world-us-canada-39233010

[15] Bethea, C. (2017) A Doctor's View of Obamacare and Trumpcare from Rural Georgia.

http://www.newyorker.com/news/news-desk/what-health-care-means-in-clay-c ounty

[16] Smith, S.E. (2017) The AHCA Could Destroy American Mental Healthcare. https://www.bustle.com/p/the-ahca-could-destroy-american-mental-health-car e-55814

[17] Scott, D. (2017) A Majority of Americans Now Say They Like Obamacare. That's a First.

https://www.vox.com/policy-and-politics/2017/6/23/15861450/poll-obamaca re-medicaid-ahca-bettercare-republican-plan

[18] Dena, B. (2018) AARP Urges Court to Keep Health Law Intact. https://www.aarp.org/politics-society/advocacy/info-2018/aarp-files-amicus-b rief-texas-aca-lawsuit.html

[19] CNBC (2018) New Kaiser Poll Finds 75\% of Americans Want to Keep ACA Protections for Pre-Existing Conditions That GOP Lawsuit Seeks to Overturn. https://www.cnbc.com/2018/09/04/poll-70percent-of-people-want-aca-protec tions-that-lawsuit-seeks-to-repeal.html

[20] Managed Care (2018) Public Wants to Keep ACA Coverage for Preexisting Conditions.

https://www.managedcaremag.com/dailynews/20180627/public-wants-keepaca-coverage-preexisting-conditions

[21] United States Census Bureau (2018) Hispanic Heritage Month 2018.

[22] United States Census Bureau (2018) Hidalgo County, Texas.

[23] Data USA (2018) Hildago County, TX.

https://datausa.io/profile/geo/hidalgo-county-tx

[24] IHME (2016) Country Profile: Hidalgo County, Texas. http://www.healthdata.org/sites/default/files/files/county_profiles/US/2015/ County_Report_Hidalgo_County_Texas.pdf

[25] Bailey, G. (2016) Commentary: UTRGV Medical School Short of Funds. http://www.themonitor.com/opinion/columnists/article cd390270-925c-11e6aeb0-e3c9383e2350.html

[26] Boje, D.M. (2001) Narrative Methods for Organizational \& Communication Research. Sage, London, Thousand Oaks, New Delhi.

[27] Booms, B.H. and Bitner, M.J. (1981) Marketing Strategies and Organization Structures for Service Firms. In: Marketing of Services, American Marketing Association, Chicago, 47-51.

[28] Parasuraman, A., Zeithaml, V.A. and Berry, L.L. (1988) Servqual. Journal of Retailing, 64, 12-40.

[29] Rosenbaum, S. (2011) The Patient Protection and Affordable Care Act: Implications for Public Health Policy and Practice. Public Health Reports, 126, 130-135. https://doi.org/10.1177/003335491112600118

[30] Zeithaml, V.A., Bitner, M.J. and Gremler, D.D. (2009) Services Marketing: Integrating. Customer Focus across the Firm. https://doi.org/10.1002/9781444316568.wiem01055

[31] Zeithaml, V.A., Bitner, M.J. and Gremler, D.D. (2010) Services Marketing Strategy. In: Sheth, J.N. and Malhotra, N.K., Eds., Wiley International Encyclopedia of Marketing, John Wiley \& Sons Ltd., Hoboken, 208-218. 
https://doi.org/10.1002/9781444316568.wiem01055

[32] Chen, Y., Fay, S. and Wang, Q. (2011) The Role of Marketing in Social Media: How Online Consumer Reviews Evolve. Journal of Interactive Marketing, 25, 85-94. https://doi.org/10.1016/i.intmar.2011.01.003

[33] Lefebvre, R.C. (2011) An Integrative Model for Social Marketing. Journal of Social Marketing, 1, 54-72. https://doi.org/10.1108/20426761111104437

[34] Ro, H. and Olson, E.D. (2014) The Effects of Social Justice and Stigma-Consciousness on Gay Customers' Service Recovery Evaluation. Journal of Business Research, 67, 1162-1169. https://doi.org/10.1016/i.jbusres.2013.05.006

[35] Ostrom, A.L., Bitner, M.J., Brown, S.W., Burkhard, K.A., Goul, M., Smith-Daniels, V. and Rabinovich, E. (2010) Moving Forward and Making a Difference: Research Priorities for the Science of Service. Journal of Service Research, 13, 4-36. https://doi.org/10.1177/1094670509357611

[36] Baron, S.L., Beard, S., Davis, L.K., Delp, L., Forst, L., Kidd-Taylor, A. and Welch, L.S. (2014) Promoting Integrated Approaches to Reducing Health Inequities among Low-Income Workers: Applying a Social Ecological Framework. American Journal of Industrial Medicine, 57, 539-556. https://doi.org/10.1002/ajim.22174

[37] Berry, L.L. and Bendapudi, N. (2007) Healthcare a Fertile Field for Service Research. Journal of Service Research, 10, 111-122. https://doi.org/10.1177/1094670507306682

[38] Berkowitz, E.N. (2010) Essentials of Healthcare Marketing. Jones \& Bartlett Publishers, Burlington.

[39] Eason, K., Waterson, P. and Davda, P. (2013) The Sociotechnical Challenge of Integrating Telehealth and Telecare into Health and Social Care for the Elderly. International Journal of Sociotechnology and Knowledge Development, 5, 14-26. https://doi.org/10.4018/ijskd.2013100102

[40] Huang, F.F., Li, A.H., Huang, J., Lai, Y.H., Yang, H.H. and Lin, C.H. (2013) Heart Disease Patient Safety Perceptions in Home Telecare Management System. Advanced Science Letters, 19, 1996-1998. https://doi.org/10.1166/asl.2013.4638

[41] Shinkman, R. (2000) Hospital Food That Draws' em in. Modern Healthcare, 30, 42-43.

[42] Bhattacherjee, A. and Hikmet, N. (2007) Physicians' Resistance toward Healthcare Information Technology: A Theoretical Model and Empirical Test. European Journal of Information Systems, 16, 725-737. https://doi.org/10.1057/palgrave.ejis.3000717

[43] HealthIT.gov (2014) 2014 Edition Test Method. http://www.healthit.gov/policy-researchers-implementers/2014-edition-final-t est-method

[44] Binder, L. (2013) The Five Biggest Problems in Healthcare Today. http://www.forbes.com/sites/leahbinder/2013/02/21/the-five-biggest-proble ms-in-health-care-today

[45] Brown, T. (2017) The Real Problem with the Healthcare Bill. https://www.nytimes.com

[46] HealthPAC Online (n.d.) Healthcare Issues. http://www.healthpaconline.net/health-care-issues.htm

[47] Cooper, Z., Craig, S.V., Gaynor, M. and Van Reenen, J. (2015) The Price Ain't Right? Hospital Prices and Health Spending on the Privately Insured (No. w21815). National Bureau of Economic Research, Cambridge. https://doi.org/10.3386/w21815

[48] United States Department of Labor (n.d.) Retirement and Healthcare Coverage...Questions and Answers for Dislocated Workers.

[49] HARVARDgazette (2009) New Study Finds 45,000 Deaths Annually Linked to Lack of Health Coverage.

http://news.harvard.edu/gazette/story/2009/09/new-study-finds-45000-deat hs-annually-linked-to-lack-of-health-coverage 
[50] Sommers, B.D., Gawande, A.A. and Baicker, K. (2017) Health Insurance Coverage and Health-What the Recent Evidence Tells Us. The New England Journal of Medicine, 377, 586-593. https://doi.org/10.1056/NEJMsb1706645

[51] Rak, S. and Coffin, J. (2013) Affordable Care Act. The Journal of Medical Practice Management. MPM, 28, 317-319.

[52] ObamaCare Facts (n.d.) ObamaCare Facts: An Independent Site for ACA Advice. https://obamacarefacts.com

[53] ObamaCare Facts (n.d.) ObamaCare Facts: Facts on the Affordable Care Act. https://obamacarefacts.com/obamacare-facts

[54] Cauchi, R. (2017) States Actions to Address Health Insurance Exchanges. http://www.ncsl.org/research/health/state-actions-to-implement-the-health-be nefit.aspx

[55] Armour, S. (2014) Rep. Issa's Committee Subpoenas Gruber over Obamacare Work.

http://blogs.wsj.com/washwire/2014/12/12/rep-issas-committee-subpoenas-g ruber-over-obamacare-work

[56] Chandler, K. (2014) Bentley Open to Medicaid Expansion Plan in Alabama. http://www.washingtontimes.com/news/2014/dec/11/bentley-open-to-medic aid-expansion-with-plan-craft

[57] HuffingtonpostPolistics (2014) Obama Defends Healthcare Law after Gruber Criticism.

http://www.huffingtonpost.com/2014/11/16/obama-defends-healthcare-grub er n 6167386.html

[58] Silver State health Insurance Exchange (2012) State of Nevada Silver State Health Insurance Exchange Consumer Assistance Report.

[59] Pearl, R. (2015) Why Healthcare Is Different If You're Black, Latino or Poor. https://www.forbes.com/sites/robertpearl/2015/03/05/healthcare-black-latin o-poor/\#156ad48e7869

[60] Patashnik, E.M. and Zelizer, J.E. (2013) The Struggle to Remake Politics: Liberal Reform and the Limits of Policy Feedback in the Contemporary American State. $\begin{array}{llll}\text { Perspectives on } \quad \text { Politics, 11, 1071-1087. } & \end{array}$ https://doi.org/10.1017/S1537592713002831

[61] Manchikanti, L., Helm, I.S., Benyamin, R.M. and Hirsch, J.A. (2017) A Critical Analysis of Obamacare: Affordable Care or Insurance for Many and Coverage for Few? Pain Physician, 20, 111-138.

[62] Bradner, E. (2017) Paul Ryan: GOP Will Repeal, Replace Obamacare at Same Time. http://www.cnn.com/2017/01/12/politics/paul-ryan-town-hall/index.html

[63] Pofeldt, E. (2017) Why 60 Percent of Small-Business Owners Want Obamacare Repealed.

http://www.cnbc.com/2017/05/05/why-60-percent-of-small-business-ownerswant-obamacare-repealed.html

[64] Riessman, C.K. (1993) Narrative Analysis. Vol. 30, SAGE Publications, Thousand Oaks.

[65] Belk, R.W., Wallendorf, M. and Sherry Jr., J.F. (1989) The Sacred and the Profane in Consumer Behavior: Theodicy on the Odyssey. Journal of Consumer Research, 16, 1-38. https://doi.org/10.1086/209191

[66] Hammersley, M. (2016) Reading Ethnographic Research. Routledge, Abingdon-on-Thames. https://doi.org/10.4324/9781315538457

[67] Blomberg, J., Giacomi, J., Mosher, A. and Swenton-Wall, P. (2017) Ethnographic Field Methods and Their Relation to Design. In: Participatory Design, CRC Press, Boca Raton, 123-155. https://doi.org/10.1201/9780203744338-7

[68] Geertz, C. (1973) The Interpretation of Culture. Basic, New York.

[69] Wallendorf, M. and Belk, R.W. (1989) Assessing Trustworthiness in Naturalistic Consumer Research. In: Hirschman, E.C., Ed., Interpretive Consumer Research, Association of Consumer Research, Provo, 69-84. 
[70] Mack, J.W., Hilden, J.M., Watterson, J., Moore, C., Turner, B., Grier, H.E. and Wolfe, J. (2005) Parent and Physician Perspectives on Quality of Care at the End of Life in Children with Cancer. Journal of Clinical Oncology, 23, 9155-9161. https://doi.org/10.1200/JCO.2005.04.010

[71] United States Census Bureau (2010) Quick Facts Hidalgo City, Texas.

[72] Lincoln, Y.S. and Guba, E.G. (1985) Naturalistic Inquiry. Sage Publications, Beverly Hills.

[73] Arnold, S.J. and Fischer, E. (1994) Hermeneutics and Consumer Research. Journal of Consumer Research, 21, 55-70. https://doi.org/10.1086/209382

[74] Griffin, S.M., Parker, D.C. and Kitchen, J. (2010) Carrying Stories from the Outside in: A Collaborative Narrative into a Teacher Education Community.

[75] Thompson, C.J., Locander, W.B. and Pollio, H.R. (1989) Putting Consumer Experience Back into Consumer Research: The Philosophy and Method of Existential-Phenomenology. Journal of Consumer Research, 16, 133-146. https://doi.org/10.1086/209203

[76] Thomas, D.R. (2006) A General Inductive Approach for Analyzing Qualitative Evaluation Data. American Journal of Evaluation, 27, 237-246. https://doi.org/10.1177/1098214005283748

[77] Schembri, S. and Ghaddar, S. (2018) The Affordable Care Act, the Medicaid Coverage Gap, and Hispanic Consumers: A Phenomenology of Obamacare. Journal of Consumer Affairs, 52, 138-165. https://doi.org/10.1111/joca.12146 


\section{Appendix}

Table A1. Brief narrative demographics of Participants.

\section{Study 1 (2014)}

1 Manuel is an undergrad student in Computer Science who splits the time between the US and Reynosa. He has a mother and a sister who are living in Reynosa. His dad is working in the US. He is 21 years old. He was raised in Mexico for his whole life but he has the US citizenship due to his birth in certain part of the border town. He has a student insurance plan in academic year due to his student status. He has never seen a doctor or visited a clinic. When he is sick, he just stays home and lets the disease cured itself.

2 Lydia is Manuel's girlfriend. She is 20 years old. She is working on her Theatre/Television/Film Degree. She is a student worker. She has six siblings, none of whom has health insurance. One of her sisters has mental illness (bipolar disorder). Like Manuel, she only had student health insurance plan when she enrolled in school.

3 Jesus is a supervisor at a media lab at a large local university. He is gay. He is 34 years old. He is living with his parents, one younger sister, and one older brother, all of them have health insurances (either private or from work). Moreover, Jesus's health insurance is premium and provided by his employer.

4 Alejandro is Jesus's full-time assistant at work. He is 29 years old. He has a bachelor degree in Business. He also has health insurance provided by the employer. He says he only goes to the hospital when it is an emergency.

5 Alex is a part-time staff at the media lab of Jesus. He does not have insurance. He did not want to disclose his age to the researchers. He looks like he is in his late $30 \mathrm{~s}$. He is a master student of political science at a large local university. He is also a part-time math teacher at a local high school. He says he hopes he will not ever have to go to the doctor.

6 Daniel is a part-time staff at the media lab of Jesus. He does not have insurance. He is 26 years old. He is also a full-time student at the local university. He does not disclose what he is studying.

7 Madelia is a former judge-retiree. She is 76 years old. She is living in one of the most expensive neighborhoods in the area. She has premium health insurance plans. She faces regular illness of the elderly and very often has to travel to San Antonia and Austin for check-up and treatment.

8 Romeo is Madelia's husband. He is 85 years old. He is an Air Force veteran. He was working as a manager for a hospital in San Antonio. He has premium health insurance plans. He has been through several surgeries (e.g. heart, back, knee) in the past 10 years.

9 Bernado is 85 years old. He is a retiree. He used to have a company, which imported agricultural products from Mexico to restaurants in the US. He has health insurance.

10 Maria is Bernado's wife. She is 83 years old. She has health insurance.

\section{Study 2 (2017)}

1 Sabastian is a single, 47 years old man who is working for a local construction company. He earns decent money as a truck driver. He has Obamacare.

2 Diego is both a fulltime graduate student and a staff at a large local university. He, his mom, and the sibling have health insurance under his dad since his employer offers health insurance. However, he will lose his coverage next year due to his age.

3 Macio is a family doctor. He is 68 years old. He used to be a faculty for a local school of medicine for a year. He got the health insurance from his employer during that time. However, after he stops working there, his health insurance will only cover him for another 6 months. He has to search for a new insurance by himself and it is very costly due to his age and patient's history.

4 Camila is Macio's wife. She is as well 68 years old. She is a retired nurse. She is under her husband's health insurance. She also has history of several severe illnesses due to her age and gene.

5 Ana is 33 years old. She is a returning student. She is living with her mother. She and her mother both have Obamacare.

6 Karina is a cleaning staff at a large local university. She is 42 . She is a single mom. She is a heavy smoker. She has three daughters who are 24,21 , and 18 . The daughters are still living with her. None of them has health insurance.

7 Alex in study 1.

8 Madelia in study 1.

9 Romeo in study 1.

10 Bernado in study 1.

11 Maria in study 1. 